\title{
The Vascular Distribution in Axillary nodes of Breast Cancer Using Color Doppler Sonography to Assess Metastasis
}

\author{
Lailatul Muqmiroh \\ Radiologic Technology Program, \\ Departement of Health Science, \\ Faculty of Vocational Studies \\ Universitas Airlangga \\ Surabaya, Indonesia
}

\author{
Heru Purwanto \\ Department of Surgery, \\ Faculty of Medicine \\ Universitas Airlangga \\ Surabaya, Indonesia
}

\author{
Lies Mardiyana, Sri Redjeki Agustiningsih \\ Departement of Radiology, \\ Faculty of Medicine \\ Universitas Airlangga \\ Surabaya, Indonesia
}

Correspondency : Lailatul Muqmiroh, lailatul.muqmiroh@ vokasi.unair.ac.id

\begin{abstract}
Background: Axillary node staging represents one of the prognostic factors in breast cancer therapy. Sonography consistently has high preoperative sensitivity and specificity in predicting status of the lymph node. Objective: To evaluate the vascular distribution using color Doppler sonography in axillary lymph node in patients with breast cancer to assess a presence of metastasis. Materials and Methods : Twenty-three breast cancer patients were used in the study (range 20-79 years old) and underwent Modified Radical Mastectomy. Patients would be performed gray scale US followed by color Doppler sonography to evaluate the vascular distribution before surgery. Histopathologic results of axillary lymph node were used to compare with US results. Diagnostic test and Chi-square test were performed to analyze the hypothesis. Results: Of 23 patients regarding features of the peripheral vascular distribution, mean age was $46.5 \pm 11.6$ yo, while $53.4 \pm 12.5$ yo for the central vascular distribution, in which most patients were belonging to age groups of 40-49 and 50-59 years, namely each age group accounted for four cases. Sensitivity, specificity, accuracy, positive predictive value and negative predictive value were $66.7 \%, 50 \%, 60.9 \%, 71.4 \%, 44.4 \%$, respectively. Chi-square test revealed no significant difference between color Doppler US and histopathologic result. Conclusion: The vascular distribution of the axillary nodes using color Doppler sonography in breast cancer patients is unsuitable enough as a diagnostic tool to assess metastasis.
\end{abstract}

Keywords-component; axillary lymph node; breast cancer; Color Doppler sonography; metastasis

\section{INTRODUCTION}

Breast cancer is the second most common cancer found in Indonesia after cervical cancer [1]. Besides the enormous number of the cases, more than $70 \%$ of the patients were found at the advanced stage [1][2]. Data from General
Directorate of Medical Service at Ministry of Health (Direktorat Jenderal Pelayanan Medik Departemen Kesehatan) show that the Case Fatality Rate (CFR) due to initial breast cancer detection was $7.2 \%$ [2]. The status of axillary lymph nodes is an important prognostic factor in women with breast cancer at an early stage and a significant point in a therapy plan [3][4][5][6][7][8][9]. In fact, not all of the patients need to have their axillary glands dissected, especially if the breast cancer is not metastatic to the axillary lymph nodes. The alternative predictor that there is a metastasis to axillary lymph nodes has been a significant element in selecting the patients who are required to undergo an axillary lymph node dissection [9][10][11][12][13][14][15][16].

Ultrasonography is a radiology modality that is commonly used to evaluate the axillary lymph nodes [8][17][18][19]. Consistently, ultrasonography has a preoperative sensitivity and relatively high specificity to predict the status of the axillary lymph nodes [8][19]. Research conducted by O'Connell et al. states that ultrasonography can show the image of enlarged axillary lymph nodes [10][8][19].

Color Doppler sonography can detect small blood vessels and evaluate the number and the distribution of blood vessels in body tissues [20]. Meanwhile, research conducted by Yang et al. in 1998 reports that the use of color Doppler sonography on axillary lymph nodes to diagnose the metastatic axillary lymph nodes of breast cancer patients has $70 \%$ of the sensitivity, $98 \%$ of the specificity, and $96 \%$ of the positive predictive value [20]. Thus, this research was conducted to investigate the metastases of breast cancer patients by analyzing the imaging of blood vessel distribution in color Doppler sonography on axillary lymph nodes. 


\section{MATERIALS AND METHODS}

Breast cancer patients who met the inclusion criteria underwent an ultrasound examination prospectively by using gray scale US to evaluate the axillary lymph nodes. After the enlarged axillary lymph nodes were found, a color Doppler sonography test was performed and the imaging of the blood vessel distribution of axillary lymph nodes was evaluated. The examination was carried out by a radiologist who did not know the medical history of the patients who were being examined. The result was confirmed with the histopathology result of the axillary lymph nodes that was the gold standard to evaluate the axillary lymph node metastases.

There are three types of the imaging of the blood vessels distribution of the axillary lymph nodes, namely central, peripheral and mixed. Central blood vessels include both the central perihilar, which means a hilar blood vessel signal that can be either simple or branched, centrifugal, either central or eccentric, and central nodal, which means a signal of blood vessels segmentation or a spot spread throughout the lymph nodes, either in a radial or aberrant multifocal form. Meanwhile, peripheral blood vessel are defined as a linear blood vessel surrounding the periphery of the lymph nodes.

Ultrasound used was LOGIC 5 (GE Health System), with a linear frequency transducer of $10 \mathrm{MHz}$. This research used an analytic observational framework research by using a diagnostic test method to identify the diagnostic value of the imaging of the blood vessel distribution during the color Doppler sonography test on the axillary lymph nodes in evaluating the metastases with histhopathological examination as a gold standard. The nominal data were collected $2 \times 2$ table and descriptively analyzed by calculating the specificity and sensitivity, the positive and negative predictive value, and the accuracy. Finally, Chi-square test or Fisher's test was performed to analyze the hypothesis.

\section{RESULTS}

Twenty-three women with breast cancer who met the inclusion criteria were gathered, examined with color Doppler sonography before Modified Radical Mastectomy was conducted and, then, moved to the Pathology Anatomy department for histopathological analysis.

\section{A. Sample Characteristics According to the Results of Color Doppler Sonography Test}

Color Doppler sonography test showed that the imaging of the peripheral blood vessel distribution was found in 14 cases $(60.9 \%)$, while the central one was found in nine cases $(39.1 \%)$.

In the imaging of the peripheral blood vessel distribution, the average age of the patients was 46.5 years old, \pm 11.6 , most of whom were in the age groups of 40-49 years old and 50-59 years old. Each group contributed four cases. Additionally, there were eight cases showing that the position of the tumor was mostly in the left breast.

The result of color Doppler sonography test on the imaging of the central blood vessel distribution illustrated that the average age was 53.4 years old, \pm 12.5 . Likewise, the majority was in the age groups of 40-49 years old and 50-59 years old, each of which contributed three cases. The position of the tumor was also mostly in the left breast, found in seven cases. The aforementioned data are summarized in Table I.

TABLE I. SAmple Characteristics based on the Result of COLOR DOPPlER SONOGRAPHY

\begin{tabular}{|l|c|c|c|}
\hline Characteristic & Peripheral & Central & Total \\
\hline No of samples & 14 & 9 & 23 \\
\hline Percentage (\%) & 60.9 & 39.1 & 100 \\
\hline Age (yo) & \multicolumn{5}{|l|}{} \\
\hline Mean age (yo) & $46.5 \pm 11.6$ & $53.4 \pm 12.5$ & \\
\hline $20-29$ & 1 & 0 & 1 \\
\hline $30-39$ & 3 & 1 & 4 \\
\hline $40-49$ & 4 & 3 & 7 \\
\hline $50-59$ & 4 & 3 & 7 \\
\hline $60-69$ & 2 & 1 & 3 \\
\hline $70-79$ & 0 & 1 & 1 \\
\hline Location & \multicolumn{5}{|l}{} \\
\hline Right breast & 6 & 2 & 8 \\
\hline Left breast & 8 & 7 & 15 \\
\hline
\end{tabular}

B. Sample Characteristics Based on the Occurrence of the Axillary Lymph Node Metastases

Histopathology analysis on the axillary lymph nodes showed that $15(65.2 \%)$ out of 23 cases indicated the metastases, while eight cases $(34.8 \%)$ did not. The average age was $45.9, \pm$ 11.057, and 55.5, \pm 12.398 , respectively. From the result of the color Doppler sonography test on the axillary lymph nodes with the imaging of the peripheral blood vessel distribution on 14 cases, 10 cases $(71.4 \%)$ indicated metastases and four cases $(28.6 \%)$ did not indicate one. Meanwhile, out of nine cases undergoing the color Doppler sonography test on the axillary lymph nodes with the imaging of the central blood vessel distribution, five cases $(55.5 \%)$ indicated metastases and four cases $(44.5 \%)$ did not indicate any. 
TABLE II. SAMPLE CHARACTERISTICS BASED ON THE AXILLARY LYMPH NODE METASTASES

\begin{tabular}{|c|c|c|c|}
\hline Characteristic & $\begin{array}{c}\text { Metastase } \\
(+)\end{array}$ & $\begin{array}{c}\text { Metastase } \\
(-)\end{array}$ & Total \\
\hline No of sample & 15 & 8 & 23 \\
\hline Percentage (\%) & $65.2 \%$ & $34.8 \%$ & $100 \%$ \\
\hline Mean of age (yo) & $45.9 \pm 11.057$ & $\begin{array}{l}55.5 \pm \\
12.398 \\
\end{array}$ & \\
\hline \multicolumn{4}{|l|}{ Color Doppler sonography } \\
\hline Peripheral & 10 & 4 & 14 \\
\hline Central & 5 & 4 & 9 \\
\hline \multicolumn{4}{|l|}{ Tumor size $(\mathbf{c m})^{*}$} \\
\hline $0-2$ & 2 & 3 & 5 \\
\hline $2-5$ & 10 & 5 & 15 \\
\hline$>5$ & 3 & 0 & 3 \\
\hline \multicolumn{4}{|l|}{ Cell differentiation* } \\
\hline Mild (well differentiated) & 2 & 2 & 4 \\
\hline $\begin{array}{l}\text { Moderate (moderately } \\
\text { differentiated) }\end{array}$ & 4 & 4 & 8 \\
\hline $\begin{array}{l}\text { Severe (poorly } \\
\text { differentiated) }\end{array}$ & 9 & 2 & 11 \\
\hline \multicolumn{4}{|l|}{ Angioinvasion* } \\
\hline Positive & 7 & 2 & 9 \\
\hline Negative & 8 & 6 & 14 \\
\hline
\end{tabular}

In reference to the size of the tumor, the majority of both the ones indicating metastases and the ones that did not show any was $2.1-5 \mathrm{~cm}$ (10 cases and five cases, respectively). Regarding the cell differentiation, based on the histopathologic result of axillary lymph nodes that indicated metastases, the majority (nine samples) was poorly differentiated. Meanwhile, based on the ones that did not indicate any metastases, the majority was moderately differentiated, shown by four cases.

In seven cases, the presence of the angioinvasion in the histopathology test indicated the metastases, while the absence of the angioinvasion in six cases showed that there were not any metastases, as shown in Table II.

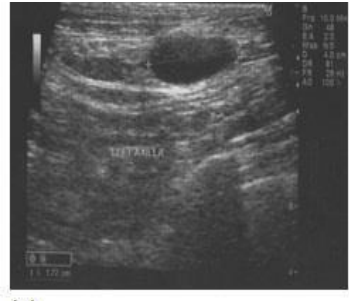

(a)

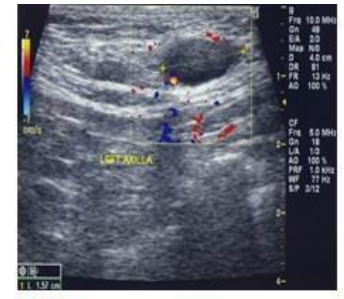

(b)
Fig. 1. Peripheral vessel distribution.

Female, 42 years old, there is an enlargement in the left axillary lymph node.

(a) Gray scale sonography showing the imaging of the lymph nodes of $1.72 \mathrm{~cm}$, fatty hilum disappeared.

(b) During the color Doppler sonography examination, the imaging of the peripheral blood vessel distribution is obvious.

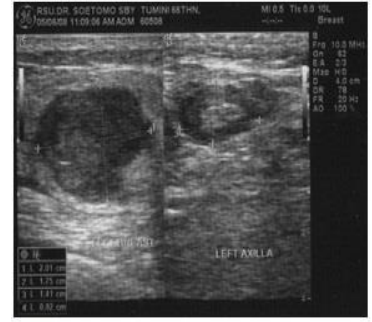

(a)

Fig. 2. Central vessel distribution. Female, 66 years old

(a) In the left side, there is a mass in the left breast. The bold edge line is irregular with the distortion of the surrounding tissues. There is a lymph node in the right side with a diameter of $1.5 \mathrm{~cm}$. There is a level surface with the imaging of an echogenic fatty hilum.

(b) The color Doppler sonography of the same patient. There is a central blood vessel distribution.

By using a diagnostic test, the imaging of the blood vessel distribution of the axillary lymph nodes in color Doppler sonography by performing a histopathological examination as a gold standard, in out of 23 cases, the result of color Doppler sonography test on the axillary lymph nodes showing the imaging of the peripheral blood vessel distribution and pathology anatomy indicating metastases (True Positive) was found in 10 cases; the result of color Doppler sonography test of the axillary lymph node showing the imaging of the central blood vessel distribution and pathology anatomy indicating the absence of metastases (True Negative) was found in four cases; the result of color Doppler sonography test on the axillary lymph nodes showing the imaging of the peripheral blood vessel distribution and pathology anatomy indicating the absence of metastases (False Positive) was found in four cases; the result of color Doppler sonography test on the axillary lymph nodes showing the imaging of the central blood vessel distribution and pathology anatomy indicating metastases (False Negative) was found 10 cases (Table III).

The imaging result of an axillary lymph node metastases process by using the imaging of the blood vessel distribution through color Doppler sonography showed sensitivity of $66.7 \%$, specificity of $50 \%$, accuracy of $60.9 \%$, positive predictive value of $71.4 \%$, and negative predictive value of $44.4 \%$ (Table III). 
TABLE III. THE ANALYSIS RESULT OF THE VASCULAR DISTRIBUTION ON THE AXILLARY LYMPH NODE THROUGH COLOR DOPPLER SONOGRAPHY BY USING HISTOPATHOLOGY TEST

\begin{tabular}{|c|c|c|c|}
\hline \multirow{2}{*}{$\begin{array}{c}\text { Color Doppler } \\
\text { US Result }\end{array}$} & \multicolumn{2}{|c|}{$\begin{array}{l}\text { Histopathology } \\
\text { Result }\end{array}$} & \multirow{2}{*}{ Total } \\
\cline { 2 - 3 } & Metastase (+) & Metastase(-) & \\
\hline Peripheral & 10 & 4 & 14 \\
\hline Central & 5 & 4 & 9 \\
\hline Total & 15 & 8 & 23 \\
\hline
\end{tabular}

McNemar test showed that there was no significant difference between the result of color Doppler sonography and Histopathology $(\mathrm{p}=$ 0.58 or $\mathrm{p}>0.05)$.

The odd ratio to analyze the relationship between the imaging of peripheral blood vessel distribution of the result of color Doppler sonography test and the axillary lymph node metastases was $1.286(0.657-2.517)$ with the $95 \%$ confidence interval.

\section{DISCUSSION}

Switchuck et al. reported the occurrence of blood flows in all enlarged lymph nodes that showed both the benign and malignant process [21]. Other studies also stated that the signal identification of color Doppler sonography in both peripheral and axillary lymph nodes (central) as the single criterion to detect axillary lymph node metastases had good sensitivity and specificity.

The prospective study conducted by Yang et al. in 1998 demonstrated a significant difference in both the imaging of the blood vessel distribution and the one of gray scale sonography on axillary lymph node, which indicated both benign and malignant process on the patients of operable primary breast cancer primer (sensitivity of $70 \%$, specificity of $98 \%$ and positive predictive value of 96\%) [22][23]. Benign process led to the imaging of the central blood vessel distribution and/or central perihilar vascularity. Meanwhile, malignant process often refers to peripheral imaging with tortuous characteristics and neovessel imaging encased by the tumor [20].

In 1998, Morton et al. described the signal of the blood flows in the hilus and the central of the reactive lymph nodes [24][25]. Other studies reported that there were blood vessel flows in all enlarged axillary lymph nodes in both the benign and malignant ones [7][25]. Therefore, it can be concluded that hilar nodal artery, medullary arterioles and sinuous capillary in the cortex become the base of both longitudinal and radial histology configuration on vascularization of normal axillary lymph nodes [26]. The correlation between histopathology and ultrasonography reported by $\mathrm{Na}$ et al. showed residual sub-capsular blood vessel in lymphoid tissues after the malignant central lymph nodes were infiltrated [26]. Recent articles have described intranodal angioarchitecture shown during the color Doppler sonography test as a reliable tool to distinguish between malignant and benign axillary lymph nodes. Benign process leads to the involvement of the entire histologic process so that the imaging of the normal central hilar blood vessel distribution can be preserved. Meanwhile, malignant process caused by the infiltration of the tumor cells causes distortion and destruction on the structure of the lymph node blood vessel [27]. Malignant tumor itself, generally, stimulates neovascularization, in terms of the secretion of angiogenesis factors [28][29][30]. The imaging of malignant lymph nodes, according to Tschammler et al., showed that there were four types of distortion angioarchitecture distortion, namely (1) encasement indicated by the curved forms of some of the intranodal blood vessels; (2) aberrant vessels indicated by one or more central blood vessels that formed an angle of more than $30^{0}$ with longitudinal lymph node axis; (3) the disappearance of the focal perfusion indicated by the disappearance of the signal flows of the blood vessels in the lymph nodes when hypervascularization occurred in the surrounding tissues; and (4) sub-capsular blood vessels indicated by short blood vessels located in the peripheral lymph nodes, which were not derived from either hilus or longitudinal blood vessels. The last type was the one that was commonly found the most [27]. If one of the four criteria is found, the malignancy will lead to lymph node malignancy. The disappearance of focal perfusion was a criterion that was first published in 1991, in reference to the presence of the angioarchitecture distortion in lymph node malignancy. Furthermore, the decrease of the perfusion and blood vessel encasement are known as perfusion pathology criteria in tumor and metastase [31][32]. Sub-capsular blood vessel is the only malignancy criterion that can be applied to hypovascular lymph nodes with short intranodal vessel segment. Sub-capsular blood vessel was initially termed accessory vessel because it was assumed to have a relationship with neovascularization. The preliminary research on the correlation between US-histopathology showed that this blood vessel 
was located in residual sub-capsular lymphatic tissue after being infiltrated in the malignant central lymph node.

This research found that the sensitivity was $66.7 \%$; the specificity was $50 \%$; the accuracy was $60.9 \%$; the positive predictive value was $71.4 \%$; and the negative predictive value was $44.4 \%$, compared to the research conducted by Yang et al. in 1998 which showed that the sensitivity was $70 \%$, the specificity was $98 \%$ and the positive predictive value was $96 \%$.

The imaging of sub-capsular blood vessel was possibly a criterion leading to a large number of false positives. Malignant criteria can be obtained from two lymph nodes suspected to be the reactive ones; however, the boundary between lymph nodes is not clear. In both nodes, there were big and small blood vessels with the branches reaching the edges, classified as subcapsular blood vessels.

Odd ratio between the result of color Doppler sonography test showed peripheral blood vessel with the occurrence of axillary lymph node metastases of $1.286(0.657-2.517)$. This indicated that the imaging of peripheral blood vessel in the color Doppler sonography test had a tendency to show lymph node metastases in pathology anatomy test, but it was not significant.

Color Doppler sonography contributes to the process of identifying the axillary lymph node metastases in breast cancer patients by providing new information, besides the axillary lymph node dissection which is related to the staging and management of breast cancer. The result of this research might be useful in diagnosing and managing breast cancer, especially at the early stage or in situ where axillary lymph node dissection should not be performed regularly, which consequently decreases the morbidity.

\section{CONCLUSION}

The diagnostic value of the imaging of the blood vessel distribution of the color Doppler sonography to evaluate metastases indicated that the sensitivity was $66.7 \%$; the specificity was $50 \%$; the accuracy was $60.9 \%$; the positive predictive value was $71.4 \%$; and the negative predictive value was $44.4 \%$. This research found that the sensitivity and the specificity levels were insufficient to make the color Doppler sonography useful as a diagnostic tool to evaluate the incidence of axillary lymph node metastases in breast cancer patients. Therefore, further research involving two radiologists in interpreting the results of color Doppler sonography test needs to be conducted to evaluate the imaging of blood vessel distribution in color Doppler sonography on axillary lymph nodes of breast cancer patients.

\section{Acknowledgment}

The writer would like to express her sincere gratitude to the late Sri Redjeki Agustiningsih for the guidance and dedication so that this research could be accomplished very well.

\section{References}

[1] Pane, M. Aspek klinis dan epidemiologi penyakit kanker payudara. Program Pasca Sarjana Ilmu Kesehatan Masyarakat Universitas Indonesia; Tinjauan Pustaka (Jakarta, 2000).

[2] Pusat Data and Informasi Kementerian Kesehatan RI. Situasi penyakit Kanker. Buletin Jendela data dan Informasi Kesehatan, Kementerian Kesehatan RI, Semester I (2015)

[3] [Alvarez, S., E. Añorbe, P. Alcorta, F. Lopez, I. Alonso, and J. Cortes. Role of sonography in the diagnosis of axillary lymph node metastases in breast cancer: A Systemic review. American Journal of Roentgenology, 186, no.5 (May 2006):1342-1348.

[4] Luini, A., G. Gatti, B. Ballardini, S. Zurrida, V. Galimberti, P. Veronesi, A.R. Vento, S. Monti, G. Viale, and U. Veronesi. Development of axillary surgery in breast cancer. Annals of Oncology, 16, no. 2 (Feb 2005): 259-262.

[5] Lyman, G.H., A.E. Giuliano, M.R. Somerfield, A.B. Benson, D.C. Bodurka, H.J. Burstein, A.J. Cochran, H.S. Cody, S.B. Edge, S. Galper, J.A. Hayman, T.Y. Kim, C.L. Perkins, D.A. Podoloff, V.A. Sivasubramaniam, R.R.Turner, R. Wahl, D.L. Weaver, A.C. Wolff, and E.P. Winer. American Society of Clinical Oncolgy Guidelines Recommendations for Sentinel Lymph Node Biopsy in Early Stage Breast Cancer. Journal of Clinical Oncology, 23, no.30 (Oct 2005): 7703-7720.

[6] Makhoul, I. Breast Cancer. Department of Medicine, University of Arkansas for Medical Sciences e medicine journal (2006).

[7] O'Connell, A.M., A. O'Doherty, and D. E Malone. Can Ultrasound Evaluate Axillary Lymph Node Status in patients With Breast Cancer? Cancer Association Radiology Journal (CARJ), 59, no. 1 (2008): 19-21.

[8] Shin, J.H., H.Y. Choi, B.I. Moon, and S.H. Sung. In Vitro Sonography Evaluation of Sentinel Lymh Nodes for Detecting Metastasis in Breast Cancer :Comparison With Histopathologic Results. Journal Ultrasound in Medicine, 23, no. 7 (July 2004): 923-928.

[9] Feu, J., F. Tresserra, R. Fábregas, B. Navarro, P.J. Grases, J.C. Suris, A. Fernández-Cíd, and X. Alegret. Metastatic Breast Carcinoma in Axillary Lymph Nodes:In Vitro US Detection. Radiology in RSNA Journal, 205, no.5 (Dec 1997): 831-835.

[10] Giuliano, Armando E., Philip I. Haigh, Meghan B. Brennan, Nora M. Hansen, Mark C. Kelley, Wei Ye, Edwin C. Glass, and Roderick R. Turner. Prospective Observational Study of Sentinel Lymphadenectomy Without Further Axillary Dissection in Patient with 
Sentinel Node-Negative Breast Cancer. Journal of Clinical Oncology, 18, no.13 (July 2000): 2553-2559.

[11] Grainger, R.E., Adam, A., D.J. Allison, and A.K. Dixon. Grainger and Allison's Diagnostic Radiology: A textbook of medical imaging. $6^{\text {th }}$ ed. (Churchill Livingstone, 2015) 957-970.

[12] Hack, Thomas F., Lorenzo Cohen, Joel Katz, Lynda S. Robson, and Paul Goss. Physical and Psychological Morbidity After Axillary Lymph Node Dissection for Breast Cancer. Journal of Clinical Oncology, 17, no. 1 (Jan 1999): 143-149.

[13] McCready, D.R., and Jacques Cantin. Axillary Dissection in The Steering Committee on Clinical Practice Guidelines for the Care and Treatment of Breast Cancer. Canadian Medical Association Journal, 158, no. 3(Feb 1998): S22-26.

[14] McMasters, K.M., T.M. Tuttle, D.J Carlson, C.M. Brown, R.D. Noyes, R.L. Glaser, D.J. Vennekotter, P.S Turk, P.S.Tate, A. Sardi, P.B. Cerrito, and M.J. Edwards. Sentinel Lymph Node Biopsy for Breast Cancer: A Suitable Alternative to Routine Axillary Dissection in Multi-Institutional Practice When Optimal Technique Is Used. Journal of Clinical Oncology, 18, no. 13 (July 2000): 2560-2566.

[15] Parmigiani, G., D.A. Berry, E.P. Winer, C.Tebaldi, J.D. Iglehart, and L.R. Prosnitz. Is Axillary Lymp Node Dissection Indicated for Early-Stage Breast Cancer? A Decision Analysis. Journal of Clinical Oncology, 17, no. 5 (May 1999): 1465-1473.

[16] Bedrosia Isabelle, Deepak Bedi, Henry M. Kuerer, Bruno D. Fornage, Lori Harker, Merrick I. Ross, Frederick C. Ames, Savitri Krishnamurthy, Beth S. Edeiken-Monroe, Funda Meric, Barry W. Feig, Jeri Akins S. Eva Singletary, Nadeem Q. Mirza, and Kelly K. Hunt. Impact of Clinicopathological Factors on Sensitivity of Axillary Ultrasonography in the Detection of Axillary Nodal Metastases in Patient with Breast Cancer. Annals of Surgical Oncology, 10, no. 9 (Nov 2003): 1025-1030.

[18] Choi, M.Y. J.W. Lee, K.J. Jang. Distinction Between Benign and Malignant Causes of Cervical, Axillary, and Inguinal Lymphadenopathy: Value of Doppler Spectral Waveform Analysis. American Journal of Roentgenology, 165, no.4 (Oct 1995): 981-984.

[19] Shetty, M.K., and W.S. Carpenter. Sonography Evaluation of Isolated abnormal Axilary Lymph Nodes Identified on Mammogram. Journal of Ultrasound in Medicine, 23 no.1 (Jan 2004): 63-71.

[20] Yang, W.T., J. Chang, and C. Metreweli. Patient with Breast Cancer: Differences in Color Doppler Flow and Gray Scale US Features of Benign and malignant Axillary Lymph Nodes. Radiology Journal, 215, no. 2 (May 2000): 568-573.

[21] Swischuk, L.E., P.B. Desai, and S.D. John. Exuberant Blood Flow in Enlarged Lymphnode: Finding on Color Flow Doppler. Pediatri Radiology Journal, 22, no. 6 (Oct 1992): 419-421.

[22] Yang, W.T., and C. Metreweli. Colour Doppler Flow in Normal Axillary Lymph Nodes. The British Journal of Radiology, 71, no. 844 (Apr 1998): 381-383.

[23] Yang, W.T., C. Metreweli, P.K. Lam, and J. Chang. Benign and malignant breast masses and axillary nodes: evaluation with echo-enhanced color power Doppler. US, Radiology Journal, 220, no. 3 (Sept 2001): 795-802.

[24] Mounford, R.A., and P. Atkinson. Doppler Ultrasound Examination of Pathologically Enlarged Lymphnode. British Journal of Radiology, 52, no. 618 (Jun 1979): 464-467.
[25] Newman, L.A. Lymphatic Mapping and Sentinel Lymph Node Biopsy for Breast Cancer Patients. Journal of Oncology Practice, 130, no. 4 (Nov 2005): 130-133

[26] Na, D.G., H.K. Lim, H.S. Byun, H.D. Kim, Y.H. Ko, and J.H. Baek. Differential Diagnosis of Cervical Lymphadenopathy:Usefulness of Color Doppler Sonography. American Journal of Roentgenology, 168, no. 5 (May 1997):1311-1316.

[26] Tschammler, A., G. Ott, T. Schang, B. Seelbach-Goebel, K. Schwager, and D. Hahn. Lymphadenopathy: Differentiation of Benign from Malignant Disease Color Doppler US Assessment of Intranodal Angioarchitecture. Radiology Journal, 208, no. 1 (Jul 1998): 117-123.

[27] Vinay, K., A.K. Abbas, and J.C. Aster. Robbins and Cotran: Pathologic Basis of Disease, $9^{\text {th }}$ ed. (Elsevier Saunders, 2015) 579-629.

[28] Roses, D.F., A.D. Brooks, M.N. Harris, R.L. Shapiro, and J. Mitnick. Complication of Level I and II Axillary Dissection in the Treatment of Carcinoma of the Breast. Annals of Surgery Journal, 230, no. 2 (Aug 1999): 194.

[29] Fox, S.B., K.C. Gatter, and A.L.Harris. Tumour Angiogenesis. Journal of Pathology, 179 (Jul 1996): 232-237.

[30] Tschammler, A., H. Wirkner, G. Ott, and D. Hahn. Vascular patterns in reactive and malignant lymphadenopathy. Eur Radiology, 6, no. 49 (1996): 473480.

[31] Veronesi, U., F. Rilke, A.S. Luini, V. Sacchini, V. Galimberti, T. Campa, E. D. Bei, M. Greco, A. Magni, M. Merson, and V. Quagliuolo. Distribution of Axillary Node Metastases by Level of Invasion. Cancer, 59, no. 4 (Feb 1987): 682-687. 